\title{
A dynamic chemical network for cystinuria diagnosis
}

\begin{abstract}
Maria Lafuente, Jordi Solà* and Ignacio Alfonso*[a]
Abstract: The study of molecular networks represents a conceptual revolution in chemistry. Building on previous knowledge and after understanding the rules of non-covalent interactions, the design of stimulus-responsive chemical systems is possible. Here we report a new strategy, based on the reorganization of a dynamic chemical network that generates new fluorescent associations in the presence of cysteine or cystine. The binding and sensing units are encoded in the components that dynamically assemble and disassemble responding to external stimuli as a successful tool to detect both cysteine and cystine in aqueous media. Moreover, the dynamic sensing system works in human urine, as a prospective application for cystinuria diagnosis.
\end{abstract}

Traditionally studying pure compounds, chemists have a new methodology to face their challenges ${ }^{[1]}$ The understanding of the emergent properties in complex molecular systems opens opportunities to work with complexity. ${ }^{[2]}$ The use of dynamic, reversible reactions has led to the preparation of complex exchanging systems ${ }^{[3]}$ while the current analytical tools allow dealing with complex mixtures. ${ }^{[4]}$ Inspired by the cellular signaling, ${ }^{[5]}$ we envisioned the preparation of artificial networks that mimic the transfer of information and produce a chemical response, ${ }^{[6]}$ like a readable signal. ${ }^{[7]}$ Specifically, we present a dynamic system able to selectively sense a biologically-relevant analyte, cysteine, in its reduced or its oxidized forms (cystine) in aqueous media and in a biofluid (urine) for diagnostic application.

Biological thiols, such as cysteine (Cys) or glutathione (GSH), play essential roles in the cell cycle. ${ }^{[8]}$ Thus, GSH is responsible for maintaining the redox cycle ${ }^{[9]}$ and Cys is involved in protein synthesis and metabolism. ${ }^{[10]}$ We focused on cystinuria, a disorder of cysteine and dibasic amino acids transport that produces stones in kidneys, bladder, and ureters due to the insolubility of its oxidized dimer, cystine. ${ }^{[11]}$ Diagnosis of cystinuria may be done by the observation of crystals in urine, or by the sodium-nitroprusside test, which leads to false-positives in patients taking acetylcysteine. ${ }^{[12]}$ An alternative is ion-exchange chromatographic quantitation, which requires derivatization and calibration. ${ }^{[13]}$ Despite the molecular sensors reported for Cys, selectivity against other biothiols is still an issue. ${ }^{[14]}$ Moreover, most of these sensors require the presence of the free thiol, precluding the detection of cystine. ${ }^{[15]}$ With these challenges in mind, we designed a molecular network that yields a fluorescence response in the presence of cysteine or cystine. The network is based on a dynamic covalent library of pseudopeptidic building blocks (BBs) ${ }^{[16]}$ upon disulfide exchange. ${ }^{[17]}$ We discovered that mixing equimolar amounts of BB 1, 2 and $3 a$ (Figure 1) at $\mathrm{pH}$ close to neutrality in aqueous media resulted in the almost exclusive

[a] Ms. M. Lafuente, Dr. J. Solà and Dr. I. Alfonso Department of Biological Chemistry and Molecular Modeling IQAC-CSIC

Jordi Girona 18-26. Barcelona 08034. Spain

E-mail: jordi.sola@iqac.csic.es; ignacio.alfonso@iqac.csic.es

Supporting information for this article is given via a link at the end of the document.((Please delete this text if not appropriate)) assembly of the heterotrimer $\mathbf{4 a}$. This selectivity is due to the selfrecognition mediated by non-covalent interactions between the different functionalities of the constituents (Figure 1B). ${ }^{[17]}$
A<smiles>O=C(N[C@@H](CS)C(=O)O)c1cc(C(=O)N[C@@H](CS)C(=O)O)cc(C(=O)N[C@@H](CS)C(=O)O)c1</smiles><smiles>NC(=O)CC(NC(=O)CS)C(=O)Nc1cccc(NC(=O)[C@H](CC(N)=O)NC(=O)CS)c1</smiles>
$\overbrace{\mathrm{NH}(\mathrm{R})}^{\mathrm{OH}} \begin{aligned} & \text { 3a: } \mathrm{R}=\mathrm{H} \\ & \text { 3c: } \mathrm{R}=\mathrm{COCH}_{3}\end{aligned}$<smiles>NC(CS)C(=O)Nc1ccc2ccc3cccc4ccc1c2c34</smiles><smiles>NC(CCC(=O)NC(CS)C(=O)NCC(=O)O)C(=O)O</smiles>

C

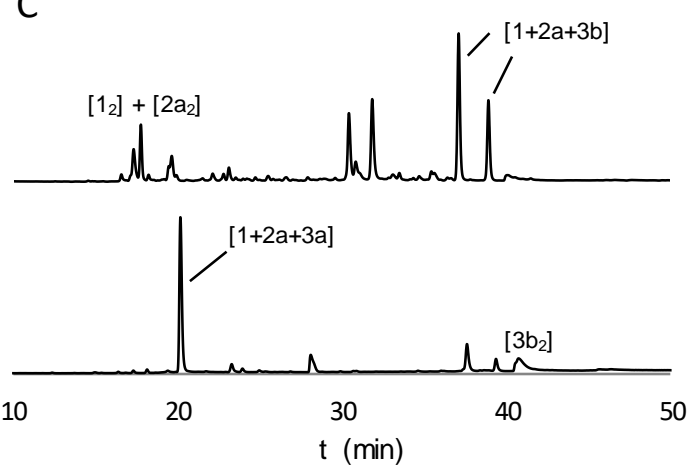

Figure 1. (A) Chemical structures of the BBs. (B) Mixing BBs 1-2-3b produces a complex mixture. The addition of $3 \mathbf{a}$ leads to the formation of heterotrimer $4 \mathbf{a}$ and the homodimer [3b]2. (C) HPLC traces for the oxidized mixtures of 1-2-3b (up) and 1-2-3b-3a (down). 
We anticipated that by replacing cysteine (3a) with a different monothiol containing a fluorophore with a lesser tendency to form the corresponding heterotrimer $(\mathbf{3 b})$, a complex mixture would occur. Addition of $\mathbf{3 a}$ to this library would lead to the most stable $\mathbf{4 a}$, with the concomitant redistribution of the dynamic mixture, releasing the fluorophore as its disulfide homodimer. This conversion could be read in the fluorescence spectra due to the formation of excimers ${ }^{[18]}$ (Figure 1B).

After exploring different candidates (Figure S35), we selected 3b with suitable fluorescence spectra of its reduced and oxidized

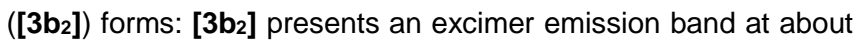
$500 \mathrm{~nm}$ that is absent in the monomer, which is characterized by a low-wavelength band with fine structure (c.a. 350-450 nm). After optimization, we found that a library containing 1 and $2(0.1 \mathrm{mM}$ each), and $3 \mathbf{b}(0.05 \mathrm{mM})$ minimized the formation of $\left[3 \mathbf{b}_{2}\right]$ homodimer, with almost no excimer emission (Figure 2, blue trace). When cysteine was added to the reaction the excimer band increased (Figure 2, red) due to the formation of [3 $\left.\mathbf{b}_{2}\right]$.

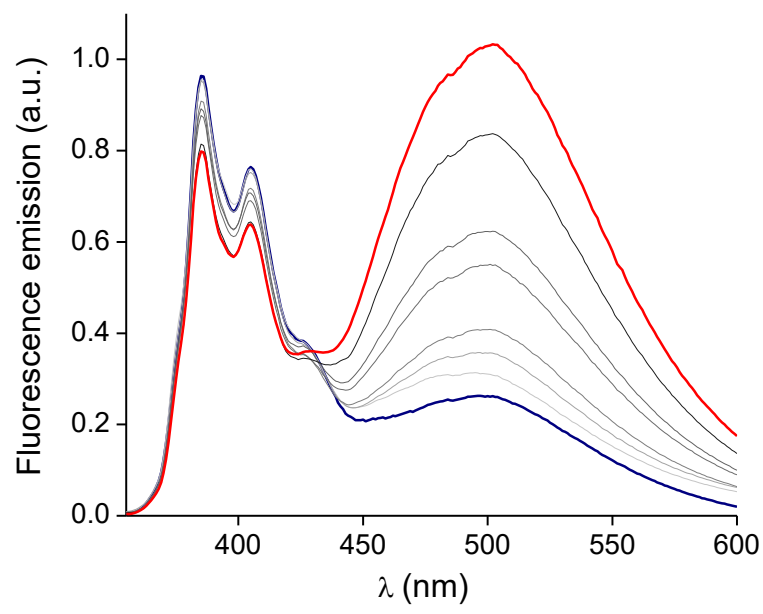

Figure 2. Fluorescence emission spectra of the dynamic library (25\% DMSO in aqueous bis-tris buffer at $\mathrm{pH}$ 6.5) and under increasing concentrations of Cys (0.025-2.5 mM). Samples were 34-times diluted in 1:1 $\mathrm{H}_{2} \mathrm{O}$ :DMSO for the measurements.

The emission at $501 \mathrm{~nm}$ was detected with a Cys concentration of $50 \mu \mathrm{M}$ and increasing the concentration of 3a resulted in an increase of the fluorescent response (Figure 2). This can be ratiometrically read by the excimer $(501 \mathrm{~nm})$ over monomer $(385 \mathrm{~nm})$ intensity ratio. Considering this ratio, the response to the presence of cysteine goes from $1.4(50 \mu \mathrm{M})$ to 3.8 $(1 \mathrm{mM})$ times the blank. Since the normal presence of Cys in urine is $\sim 35 \mu \mathrm{M}$ and the occurrence of stone-producing cystinuria starts from approximately $0.8 \mathrm{mM}$, our method fits within these values.

Thanks to the dynamic nature of the sensing system based on disulfide formation and exchange, $\left[3 \mathbf{a}_{2}\right]$ behaved similar to $3 \mathbf{a}$ (Figure $3 \mathrm{~A}$, red and green traces). This ability allows detecting cysteine in its reduced or oxidized forms in aqueous media without an extra preparation step.
Regarding the selectivity against different biothiols, the system gives almost no response to the presence of other biologically relevant cysteine derivatives like GSH (Figure $3 \mathrm{~A}$, blue) or $\mathrm{N}$-acetylcysteine (Figure $3 \mathrm{~A}$, orange), overcoming falsepositives. The selectivity for $\mathbf{3} \mathbf{a}$ and $\left[\mathbf{3} \mathbf{a}_{2}\right]$ is illustrated in Figure $3 B$ by the excimer/monomer ratio plot, and can be explained by the specific recognition motif within the folded conformation of 4 a that is precluded with GSH and acetylcysteine. Additionally, we tested the behavior of the sensing network in the presence of the amino acids that can be found in urine. We started with the basic amino acids (Lys, Orn, Arg), because they also show high values in cystinuria patients. Gratifyingly, the dynamic sensor is able to detect $\mathbf{3} \mathbf{a}$ (Figure $3 \mathrm{C}$ ) and $\left[\mathbf{3} \mathbf{a}_{2}\right]$ (Figures S71) in the presence of these basic amino acids at concentrations in the upper limit of the expected in regular urine samples. More importantly, the sensor also provides a clear readout of $\mathbf{3} \mathbf{a}$ or cystine in the presence of pathological concentrations of these amino acids (Figure S72). This highlights the robustness of the network sensor, which is able to detect the analytes in the presence of high concentrations of basic amino acids.
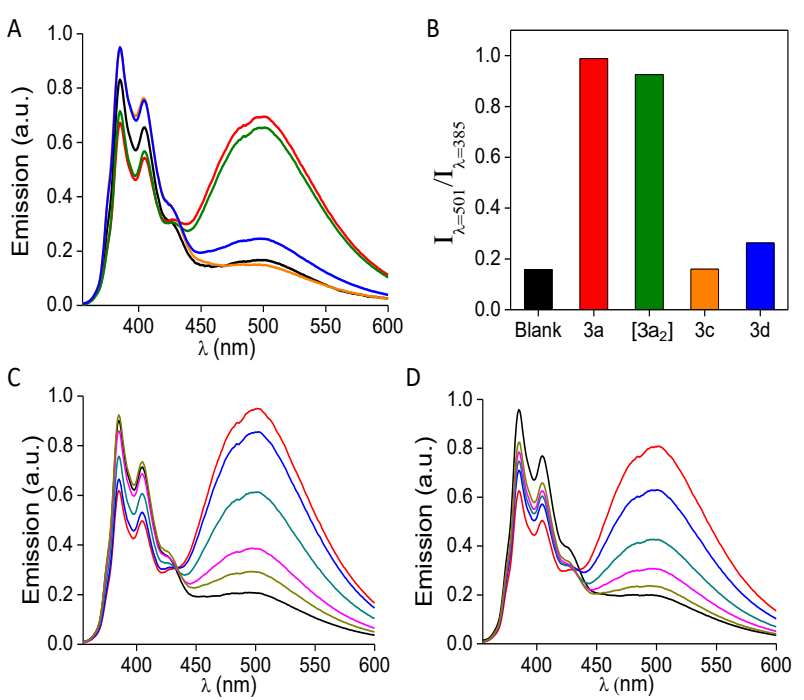

Figure 3. (A) Fluorescence emission spectra of the library alone (black) and in the presence of $0.5 \mathrm{mM}$ Cys (red), $0.25 \mathrm{mM}$ cystine (green), $0.5 \mathrm{mM} \mathrm{N}$-acetylCys (orange) and $0.5 \mathrm{mM} \mathrm{GSH}$ (blue). (B) Plot of the excimer/monomer ratio for the different biothiols. $(C)$ Sensing of Cys $(0.05-1.0 \mathrm{mM})$ in the presence of the three basic amino acids (Lys, Orn and Arg) at a typical concentration found in urine. (D) As in (C) but in a buffer containing (Lys, Orn, Arg, Asn, Gly, Ala, His, Asp, $\beta$-Ala, Ser, Tyr and Met). Samples were 34-times diluted in 1:1 $\mathrm{H}_{2} \mathrm{O}$ :DMSO for the measurements.

The sensor also responded to minute concentrations of both 3a and $\left[\mathbf{3}_{2}\right]$ in very competitive media containing most of the amino acids that can be found in urine (Lys, Orn, Arg, Asn, Gly, Ala, His, Asp, $\beta$-Ala, Ser, Tyr, Met) at their normal concentrations (Figure 3D and Figures S73-75).

Once we had evaluated the sensitivity and the selectivity of the method, we tested the system in urine samples from healthy volunteers (ESI). We measured the fluorescence spectra of the urine without sensor to confirm that no other metabolites in this 
fluid could interfere (Figure 4A, black). We also measured the positive response of the sensor to the naturally excreted cysteine in the urine samples (light blue spectrum in Figure $4 \mathrm{~A}$ and $\mathrm{U}$ samples in Figure 4B). Moreover, the addition of cysteine into these samples produced the increase of the band at $501 \mathrm{~nm}$, with a detection range that goes from normally occurring Cys in urine (blue points in Figure 4B) to pathological concentrations (red). Thus, we could also sense abnormal concentrations of cysteine that would not yet cause calculi (green).
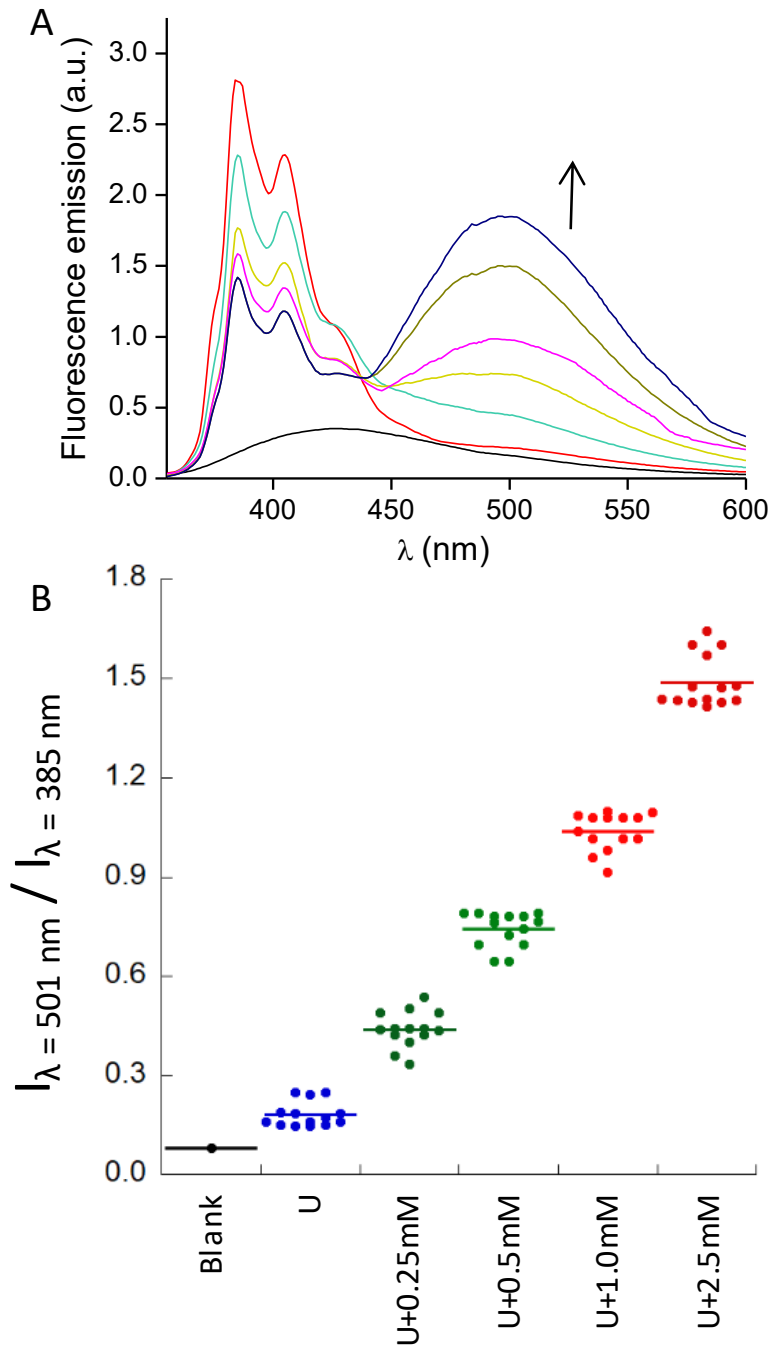

Figure 4. (A) Selected normalized fluorescence spectra of urine (black), sensor alone (red), sensor + urine (light blue) and after increasing concentrations of added Cys (0.25-2.5 mM). (B) Scatter plot of the excimer/monomer emission of the library alone (Blank), for different urine $(U)$ samples of healthy volunteers and for the urine samples plus additional Cys. Samples were 34-times diluted in $1: 1 \mathrm{H}_{2} \mathrm{O}$ :DMSO for the measurements.

In conclusion, we described a rationally designed dynamic molecular network able to selectively sense biologically relevant molecules. Instead of a discrete fluorescent probe, the sensor comprises an ensemble of species that rearranges and releases a fluorescent reporter in response to the analyte. This system works in aqueous media to selectively sense cysteine and cystine against other biothiols and amino acids, even in human urine. Our work shows the potential of chemical networks to achieve advanced functions, on the road towards 'artificial' life. ${ }^{[19]}$

\section{Acknowledgements}

Financial Support from MINECO/FEDER (CTQ2015-70117-R and BES-2013-063128), AGAUR (2014 SGR 231) and European Union (COST CM1304) are gratefully acknowledged

Keywords: systems chemistry • dynamic networks • sensors • pseudopeptides $\cdot$ cystinuria

[1] (a) P. T. Corbett, J. Leclaire, L. Vial, K. R. West, J.-L. Wietor, J. K. M. Sanders, S. Otto, Chem. Rev. 2006, 106, 3652; (b) R. F. Ludlow, S. Otto, Chem. Soc. Rev. 2008, 37, 101; (c) E. Mattia, S. Otto, Nat. Nanotechnol. 2015, 10, 111; (d) G. Ashkenasy, T. M. Hermans, S. Otto, A. F. Taylor Chem. Soc. Rev. 2017,46, 2543.

[2] (a) J. R. Nitschke, Nature, 2009, 462, 736; (b) J.-M. Lehn, Angew. Chem Int. Ed. Engl. 2013, 52, 2836; Angew. Chem. 2013, 125, 2906 . (c) I. Alfonso, Chem. Commun. 2016, 52, 239.

[3] (a) M. Barboiu. Constitutional Dynamic Chemistry: Bridge from Supramolecular Chemistry to Adaptive Chemistry. Springer-Verlag Berlin Heidelberg 2012; (b) J.-M. Lehn, A. V. Eliseev. Science. 2001, 291, 2331 (c) J. Li, P. Nowak, S. Otto, J. Am. Chem. Soc. 2013, 135, 25, 9222; (d) D. Kamárony, M. Tezcan, G. Schaeffer, I. Marić, S. Otto, Angew. Chem. Int. Ed. 2017, 56,14658; Angew. Chem. 2017, $129,14850$.

[4] (a) S. Otto, Acc. Chem. Res. 2012, 45, 2200; (b) S. N. Semenov, L.J.Kraft, A. Ainla, M. Zhao, M. Baghbanzadeh, V. E. Campbell, K. Kang, J. M. Fox, G. M. Whi tesides, Nature 2016, 537, 656; (c) A. M. Valdivielso, F. PuigCastellvi, J. Atcher, J. Solà, R. Tauler, I. Alfonso, Chem. Eur.J. 2017, 23,10789 .

[5] (a) M. I. Simon, M. P. Strathmann, N. Gautam, Science, 1991, 252, 802; (b) J. Schlessinger, Cell, 2000, 103, 211.

[6] (a) A. P. de Silva, H. Q. N. Gunaratne, T. Gunnlaugsson, A. M. Huxley, C. P. McCoy, J. T. Rademacher, T. E. Rice, Chem. Rev., 1997, 97, 1515 (b) E. V. Anslyn, J. Org. Chem., 2007, 72, 687; (c) L. You, D. Zha, E. V. Anslyn, Chem. Rev. 2015, 115, 7840; (d) M. H. Lee, J. S. Kim, J. L. Sessler, Chem. Soc. Rev., 2015, 44, 4185.

[7] Selected examples: (a) E. G. Shcherbakova, T. Minami, V. Brega, T. D. James, P. Anzenbacher Jr, Angew.Chem. Int. Ed. 2015, 54, 7130 Angew. Chem. 2015, 127, 7236; (b) R. Berardozzi, E. Badetti, N. A. C. dos Santos, K. Wurst, G. Licini, G. Pescitelli, C. Zonta, L. Di Bari, Chem. Commun. 2016, 52, 8428; (c) P. Zardi, K. Wurst, G. Licini, C. Zonta, J. Am. Chem. Soc. 2017, 139, 15616; (d) G. Gasparini, F. Bettin, P. Scrimin, L. J. Prins, Angew. Chem. Int. Ed. 2009, 48, 4546; Angew. Chem. 2009, $121,4616$.

[8] (a) Z. A. Wood, E. Schröoder, J. Robin Harris, L. B. Poole, Trends Biochem. Sci., 2003, 28, 32; (b) R. O. Ball, G. Courtney-Martin, P. B. Pencharz, J. Nutr., 2006, 136, 1682 S.

[9] (a) A. Meister, M. E. Anderson, Annu. Rev. Biochem 1983, 52, 711; (b) C. Perricone, C. De Carolis, R. Perricone, Autoimmun. Rev. 2009, 8, 697; (c) R. Franco, O. Schoneveld, A. Pappa, M. Panayiotidis, Arch. Physiol. Biochem. 2007, 113, 234.

[10] (a) N. M. Giles, G. I. Giles, C. Jacob, Biochem. Biophys. Res. Commun 2003, 300,1 (b) V. Gazit, R. Ben-Abraham, R. Coleman, A. Weizman, Y. Katz, Amino Acids 2004, 26, 163.

[11] E. Fjellstedt, L. Harnevik, J.-O. Jeppsson, H.-G. Tiselius, P. Söderkvist, T. Denneberg, Urol. Res. 2003. 31, 417.

[12] C. S. Biyani, J. J. Cartledge, Eau-Ebu update series, 2006, 4, 175. 
[13] R. E. Grier, W. A. Gahl, T. Cowan, I. Bernardini, G. A. McDowell, P. Rinaldo, Genet. Med. 2004, K, 66.

[14] (a) X. Chen, Y. Zhou, X. Peng, J.Yoon, Chem. Soc. Rev. 2010, 39, 2120; (b) H. S. Jung, X. Chen, J. S. Kim, J. Yoon, Chem. Soc. Rev., 2013, 42 6019; (c) L.-Y Niu, Y.-Z. Chen, H.-R. Zheng, L.-Z. Wu, C.-H. Tung, Q.-Z. Yang, Chem. Soc. Rev. 2015, 44, 6143. (d) C.-X. Yin, K.-M. Xiong, F.-J. Huo, J. C. Salamanca, R. M. Strongin, Angew. Chem. Int. Ed. 2017 56,13188; Angew. Chem. 2017, 129,13368

[15] Seleted examples (a) H. Maeda, H. Matsuno, M. Ushida, K. Katayama K. Saeki, N. Itoh, Angew. Chem. Int. Ed. 2005, 44, 2922; Angew. Chem. 2005, 117, 2982; (b) S. Sreejith, K. P. Divya and A. Ajayaghosh, Angew. Chem., Int. Ed., 2008, 47, 7883; Angew. Chem. 2008, 120, 8001; (c) J. Liu, Y.-Q. Sun, Y. Huo, H. Zhang, L. Wang, P. Zhang, D. Song, Y. Shi, W. Guo, J. Am. Chem. Soc. 2014, 136, 574; (d) D. Zhang, Z. Yang, H

Li, Z. Pei, S. Sun,Y. Xu, Chem. Commun. 2016, 52, 749; (e) X. Sun, Eric V. Anslyn, Angew. Chem. Int. Ed. 2017, 56, 9522; Angew. Chem. 2017 129, 9650; (f) M. Zhang, M. L. Saha, M. Wang, Z. Zhou, B. Song, C. Lu, X. Yan, X. Li, F. Huang, S. Yin, P. J. Stang, J. Am. Chem. Soc. 2017 139, 5067; (g) F. Y. Thanzeel, C. Wolf, Angew. Chem. Int. Ed. 2017 56 ,7276; Angew. Chem. 2017, 129, 7382.

[16] J. Atcher, J. Solà, I. Alfonso, Org. Biomol. Chem. 2017, $15,2013$.

[17] M. Lafuente, J. Atcher, J. Solà, I. Alfonso, Chem. Eur. J. 2015, 21,17002.

[18] S. Nishizawa, Y. Kato, N. Teramae, J. Am. Chem. Soc. 1999, 121, 9463.

[19] (a) A. de la Escosura, C. Briones, K. Ruiz-Mirazo, J. Theor. Biol. 2015, 381, 11; (b) K. Ruiz-Mirazo, C. Briones, A. de la Escosura, Chem. Rev. 2014, 114, 285. 
Entry for the Table of Contents (Please choose one layout)

Layout 1:

\section{COMMUNICATION}

A dynamic covalent chemical system rearranges in the presence of cysteine and cystine to render a fluorescent signal. The chemical system can be used to detect pathological amounts of the biothiol in urine.

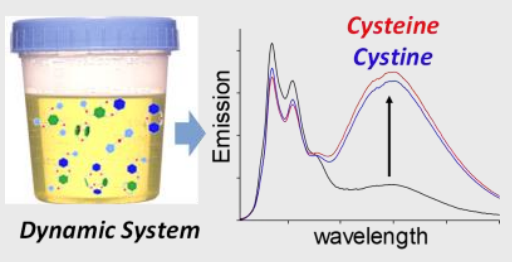

M. Lafuente, J. Solà, I. Alfonso

Page No. - Page No.

A dynamic chemical network for cystinuria diagnosis

Layout 2:

\section{COMMUNICATION}

Author(s), Corresponding Author(s)*

Page No. - Page No.

Title 